\title{
الإملاء فى الكتابة
}

\section{Bambang Hermanto}

Dosen STIT Al-Karimiyyah Sumenep

أ الإملاء

الإملاء لغة هو الإمهال والتأخير، وإطالة الوقت والعمر حتى يتسع الزمن للتمتع

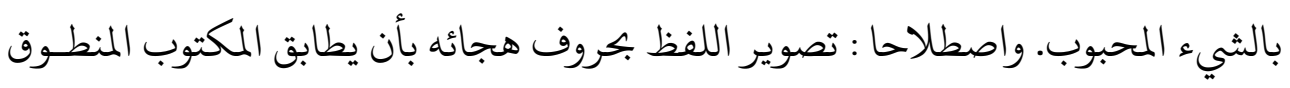

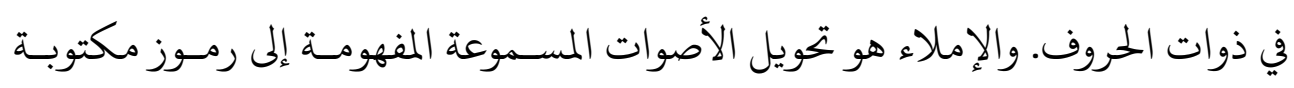

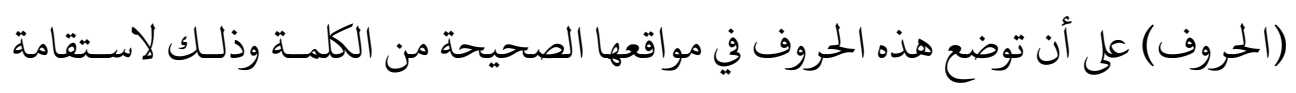

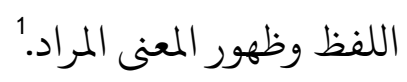

والإملاء درس من دروس اللغة العربية، فهو من الأسس الهامة للتعبير الكتـابي، المرادي، لأنه وسيلة من حيث الصورة الخطية. والخطأ الإملاء يشوه الكتابة، وقد يعوق فهم جملـة، كما أنه يدعو إلى احتقار الكاتب وازدرائه.

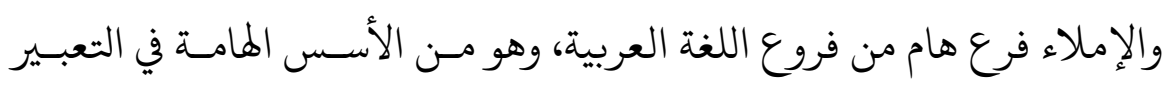

الكتابي، ووسيلة الاتصال التي يعبر بها الفرد عن أفكاره. والرسم وهو يسمى اليوم بالإملاء، فرونه

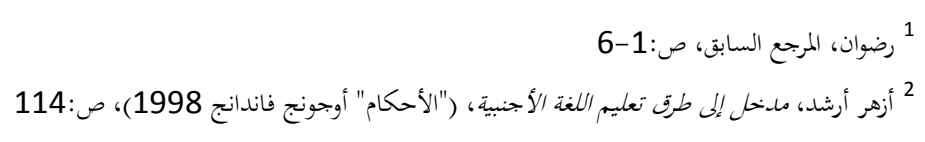

Kariman, Volume 06, Nomor 02, Desember 2018|289 


\section{Bambang Hermanto}

فن له مقومات وأصول راعي القدماء فيها اعتبارات شتى، بعضـها يرجـح إلى التيسـير في رسم الكمات الشائعة الكثيرة الاستعمال.3

الإملاء هو تحويل الأصوات المسموعة المفهومة إلى رموز مكتوبة (الحروف) على

أن توضع هذه الحروف في مواضعها الصحيحة من الكلمة وذلك لاستقامة اللفـظ وظهـور المعنى المراد، وقد تصكون هذه الأصوات مساوية تماما للرموز، فيكون لكل صـوت رمـزه، كما قد تكون بعض هذه الحروف غير مصوتة، وهنا يقع الالتبـاس عنـــ الممـلي عليـه، فيقع في الخطأ.

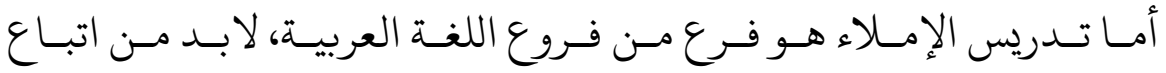

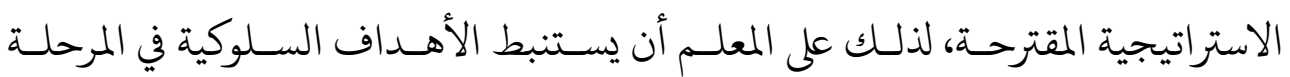
الإبتدائية يطالب التلميذ بنسخ موضوعات الكتاب المقررة في البيت، وذلك يقـوى مـن إرادة التلميذ ويشعره بالمسؤولية تجاه المدرسة، لذا يركز التربويون على الواجبات المدرسية ولكن ذونمام إرهاق للتلميذ، ولكنها تعمل في نفسىـ الوقـت على ربــ ذهـن التلميـذ بالمادة المتعلمة، وبالمدرسة، وبالمعلمين وهذا الإحساس يعتبر في حد ذاته هـدف مرغـوب فيه.

من بعض المعلمين والمتعلمـين يهسـبوا أن درس الإمـلاء مـن الدرس المحـدودة الفاعلية، وأنه ينحصر في حدود رسم الكلمة رسما صحيحا، ليس غير. إذ ثمة غايات أبعد وأوسع من وقف دروس الإملاء على رسم الكلمة الرسم الصحيحا، وإنما هو إلى جانب هذا

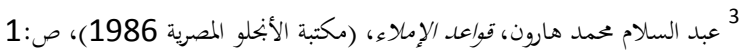

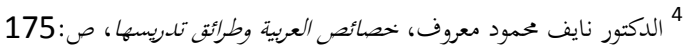

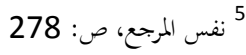


عون للتلاميذ على إنما لغـتهم وإثرائهـا، ونضـجهم العقـلي، وتربيـة قـدراتهم الثقافيـة،

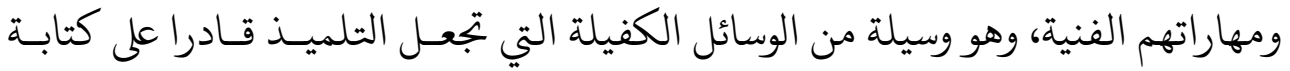

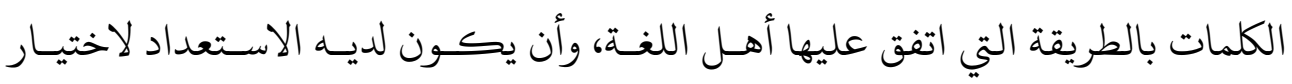

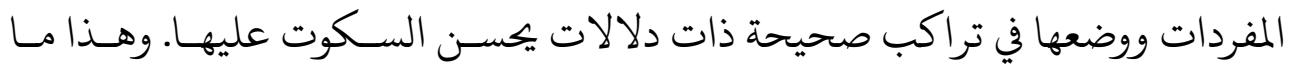
يجعلنا ندرك أن الخطأ الإملائي يشوه الكتابة، ويعوق فهم الجملة. ومــن التصـور السـابق لابد أن نتخذ من مادة الإملاء وسيلة الألوان متعددة من النشاط اللغوي، والتدريب علي كثير من المهارت، والعادات الحسنة في الكتابة والتنظيم. وغير الواجبات هنـك حصـص الخـط والحصـص بـالإملاء المنقـول، والمنظـور

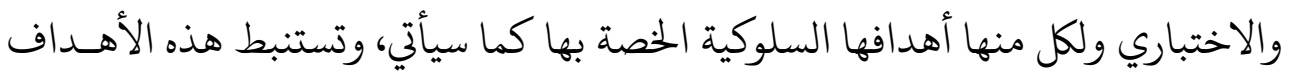
عادة من المقرر في كل سنة دارسية. ولا بد للمعلم أن يستخدم الوسائل التعليمية اللازمــة

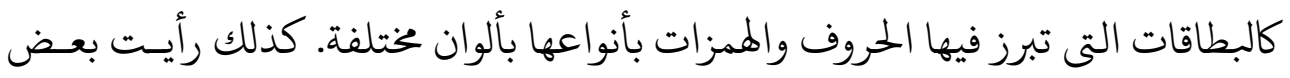

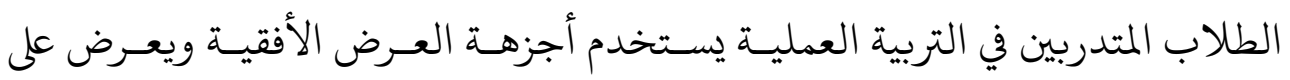
التلامذ بعض قواعد الكتابة والإملاء والخط. ولا يخفى على المعلم قيمة استخدام الوسيلة التعليميــة في تــــريس أي مـادة مـن مواد الدراسة، ومنها بالطبع مادة الكتابة والإملاء.

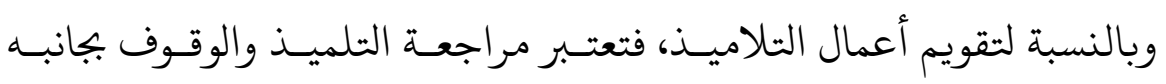

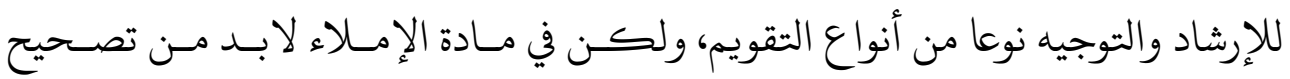
كراسة التلميد ووضع الدرجات التي يستحقها كل منهم، وعلى كل موضوع إملائي، كذلك

$$
6 \text { 6 رضوان، المرجع السابق، الإملاء نظريته وتطبيقة، ص:5-6 }
$$

Kariman, Volume 06, Nomor 02, Desember 2018| 291 


\section{Bambang Hermanto}

لابد من تصحيح أمخطئ التلاميذ وكتابتها لهم كي يعيدوا الجملـة الـتي وقـع فيهـا الخطـأ مرات عديدة، ومراجعة ما نسخه التلاميذ للتأكد من التزامهم بتصحيح الأمخطئ.

$$
\text { 1. أهمية الإملاء }
$$

في الإملاء أهمية خصة في اللغة العربية، وذلك لما يترتب على خطـأ الإمـلائي

من تغيير في صورة الكلمة، الذي بدوره يؤدي إلى تغيير معناها، ولعل أهم أهدافـه مـا

أ) تمكين الطلاب من رسم الحروف والألفاظ بشكل واضح ومقروء، أي تنميـة

$$
\text { المهارة الكتابية غير المنظورة عندهم. }
$$

ب) القدرة على تمييز الحروف المتشابهة ، رسما بعضها من بعض، بكيـث لا يقـح القارى للمادة المكتوبة في الالتباس بسبب ذلك.

ج) القدرة على كتابـة المفــردات اللغويـة الـتي يسـتدعيها الطالـب في التغبــير الكتابي.

د) تحقيق التكامل في تدريس اللغة العربية، بكيث يخـــم الإمـلاء فـروع اللغـة

$$
\text { الأخرى. }
$$

ه) تحسين الأساليب الكتابية، وإسراء الثروة اللغة، بما يكتسـبه الطالـب مسن

$$
\text { المفردات والأنماط اللغوية من خلال نصوص الإملاء التطبيقية. }
$$

و) إثراء ثروة الطالب المعرفية على أنواعها التي تزوده بهـا النصـوص الإملائيـة

الهادفة.

$$
7 \text { نفس المرجع، ص: } 278
$$


ز) تنمية دقة الملاحظة والانتباه وحسن الإصغاء.

وفي الإملاء فوائد عديدة تتصل بالمهارات اللغوية المتنوعة :

أ) الإملاء تدريب على الكتابة الصحيحة، أي التهجئة الصحيحة.

ب) الإملاء يكشف عن قدرة المتعلم على التمييز بين الأصوات اللغوية.

ج) الإملاء يعزز معرفة المتعلم بالمفردات والتركيب اللغوية.

د) الإملاء يكشف عن قدرة المتعلم على الترقيم الصحيح. 9

وتعليم الإملاء هـو خطـوات منظمــة يقـوم بهـا التلميـذ تمكنـه مـن فهـم

واستيعاب مهارة الكتابة معينة، تتكون لديه من خلالها القـــرة على رسـم الكلمـات

رسما صحيحا.

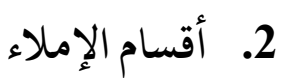

ويفهم الباحث مما سبق أن الإملاء لا تقف غايته عند هـــه الحـدود القريبـة

التى يظنها بعض المدرسين، ولكن ينبني اتخاذ الإملاء وسـيلة لألـوان متعـددة مـن

النشاط اللغوي. 10 ولذلك أن أنواع الإملاء على أربعة انواع كما يلي:

أ) ألماء المنقول

ومعنى الإملاء المنقول هو أن ينقل التلاميذ القطعة من كتاب أو سـبورة

إضافية بعد قراءتها وفهمها، وتهجى بعض كلماتها هجاء شفويا، وهذا النـوع مـن

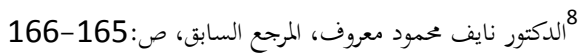

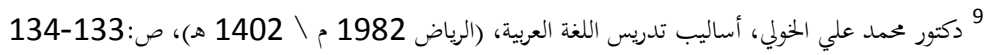

10 10 عبد العليم إبراهيم، المرجع السابق، ص: 195

Kariman, Volume 06, Nomor 02, Desember 2018|293 


\section{Bambang Hermanto}

الإملاء يلائم تلاميذ الصف الثالث من المرحلة الإبتدائية، ويمكن أن يمتد إلى تلاميذ الصف الرابع كذلك.

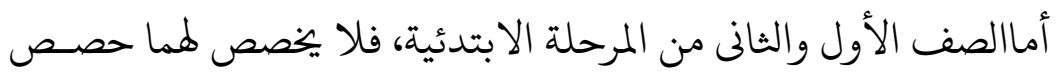

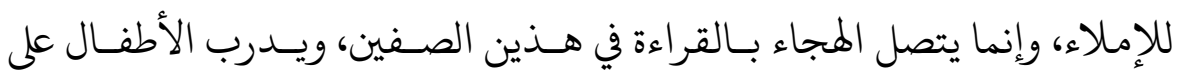
القراءة وعلى الكتابة مايقرعون في وقت واحد، بل إن تدريبهم على الهجـاء ورسـم الحروف والكلمات قد يكون في أثناء تدريبهم على الرسم، أوفي حصة الأشغال. ب) ب الإملاء المنظور

ومعنى الإملاء المنظور هــو أن تعـرض القطقــة على التلاميـــ لقراءتهـا

وفهمها، وهجاء بعض كلماتها، ثم تحجب عنهم، وتملى عليهم بعـد ذلك. وهـــا

النوع من الإملاء يلائم تلاميذ الصف الرابـع مـن المرحلـة الإبتدائيـة، ويهـوز امتداده إلى الصف الخامس كذلك على حسب مستوى التلاميذ.

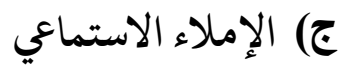

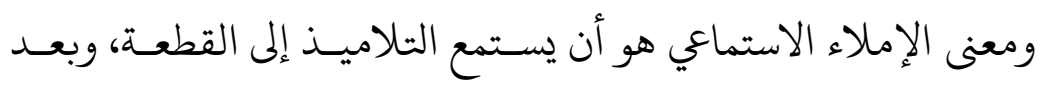

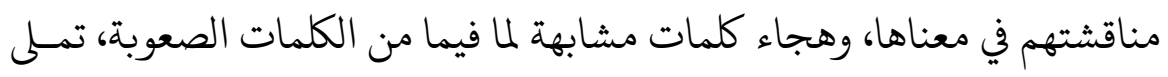
عليهم. وهذا النوع من الإملاء يلائم تلاميذ الصفين الخـامس والسـادس مـن

$$
\begin{aligned}
& \text { المرحلة الإبتدائية، وتلاميذ المرحلة الإعدادية. } \\
& \text { الإملاء الاختباري }
\end{aligned}
$$


ومعنى الإملاء الاختباري هو الغرض منه تقديرالتلاميذ، وقياس قدرته

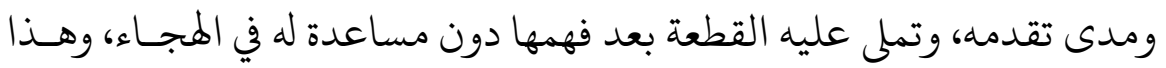

النوع من الإملاء يتبح مع التلاميذ في جميع الفرق لتحقيق الغرض الذى ذكرناه،

ولكن ينبنى أن يكـون على فـترات معقولـة، حستى تتبـع الفـرص للتـدريب

والتعليم.11

3. طريقة التدريس في الإملاء

كما عرفه الباحث أن طريقة التدريس في الإملاء فهو كما يلى:

\section{أ) ألماء إملاء المنقول}

يسير الدرس على حسب الخطوات الأتية:

1. التمهيد لموضوع القطعة على نمط التمهيد لدرس المطالعة أي بعرض النمـاذج أو الصور، واستخدام الأسئلةالمهدة.

2. عـرض القطعـة : في الكتـاب، أو البطاقـة، أو على السـبورة الإضـافية، دون أن تضيط كلماتها، حتى لاينقل التلاميذ هذا الضبط.

$$
\text { 3. قراءة المدرس القطعة قراءة نموذجية. }
$$

4. قراءات فردية من التلاميذ، ويجب الحرص على عدم مقاطعـة القـارئ لإصـلاح ح

$$
\text { خطأ وقع فيه. }
$$

$$
\text { 11 عبد العليم إبراهيم، المرجع السابق، ص: 196-197 }
$$

Kariman, Volume 06, Nomor 02, Desember 2018|295 


\section{Bambang Hermanto}

5. أسئلة في معنى القطعة للتأكيد من فهـم التلاميـذ لأفكارهـا، وفي هـــه الخطـوة تدريب للتلاميذ على التعبير الشـفوي الذى ينـبنى أن يكــون له نصـيب في كل

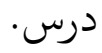

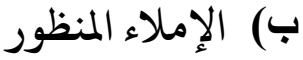

طريقة الإملاء المنظور مثل طريقة الإمـلاء المنقــول، إلا أنـهـ الانتهـاء مـنـ

القراءة ومناقشة المعنى، وتهبجى الكلمات الصعبة ونظائرها تحجـب القطعـة عـن

$$
\begin{aligned}
& \text { التلاميذ، ثم تملى عليهم. } \\
& \text { ج) الإملاء الاستماعي } \\
& \text { يسير الدرس على حسب الخطوات الأتية: } \\
& \text { 1. التمهيد : بالطريقة السابقة في المطالعة. } \\
& \text { 2. قراءة المدرس القطعة، ليلائم التلاميذ بفكرتها العامة . }
\end{aligned}
$$

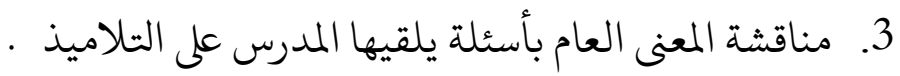

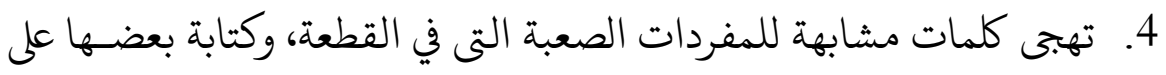
السبورة، وينبنى أن تعرض هذه الكلمات المشابهة في جمل كاملة.

$$
\text { الإملاء الاختباري }
$$

طريقة الإملاء الاختباري مثل طريقة الإملاء الاستماعي مع حذف مرحلـة

$$
\text { الهجاء. }
$$

أ) طريقة الجمع: 
وأساسها استخدام غريزة الجمع والاقتناء، وطريقـة اسـتخدامها تكليـف

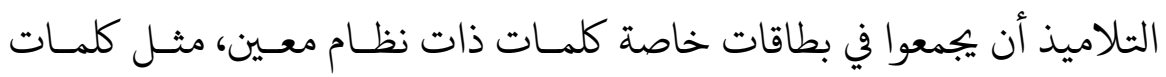

تكتب بلامين، أو كلمات تنتهى بتاء مربوطة أو تاء مفتوحة، أو كلمـات ينطـق

$$
\text { ب) اخرها ألفا ولكنها تكتب ياء. }
$$

وهي من وسائل التدريب الفردي، وطريقتها ان تعد بطاقات يكتـب فيهـا

مجموعة كبيرة من الكلمات التى تخضع كلها لقاعدة إملائية، مثل بطاقة تشـتمل على كلمات تنتهى بهمزة تكتب على السطر، أو على ألف أو واو أو يـاء، وكلمـات تتوسطها همزة على ياء أو واو، وكلمات تنتهى بألف تكتب ياء.حتى تستفي هـــه الطاقات القواعد المشهورة في الهجاء.12

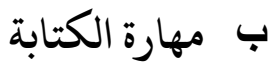

الكتابة نشاط معقد جدا، ولذلك فإن تعريف الكتابة الجيدة أمر يصعب الوصول

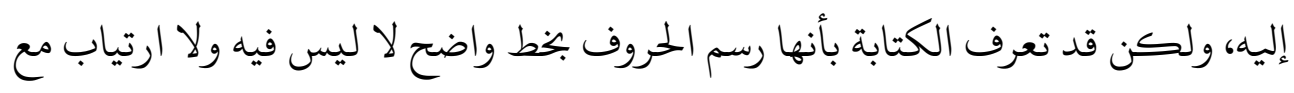

مراعات النهج السليم للكلمات وفق قواعد الكتابة العربية المتفق عليها لدى أهلها بحيث

تعطي في النهاية معنى مفيدا ودلالة معينة.

وتمثل الكتابة ركيزة أساسية في عملية الاتصال التي قامت وما زالت بدور فعال

في حفظ التراث البشرى من الضياع، وتسجيل تاريخ الإنسان عبر الأزمنة المختلفة، كما

$$
12 \text { عبد العليم إبراهيم، المرجع السابق، ص: 197- } 201
$$

Kariman, Volume 06, Nomor 02, Desember 2018|297 


\section{Bambang Hermanto}

أدى اختراع الكتابة دورا عظيما في تسجيل القران الكريم والحـديث النبــوي الثر-يف ولذا حثنا الرسول صلى الله عليه وسلم على تعلمها في قـوله "قيـدوا العلـم بالكتابـة" رواه الطبرى.

يشكل اختراع الكتابة مرحلة جديدة في تقدم الحضـارة الإنسـانية، ولا شـك أن هناك لغات كثيرة انتشرت ثم اندثرت قبل أن يتوصل العقل البشرى إلى طريقة تسجيل رموزها على أوراق البردى أو الأحجار أو الورق لكي تسـتطيع الأجيـال اللاحقـة أن تتـابع ماحدث في الماضي السحيق. لقد لعبت الكلمة المكتوبـة دورا أساسـيا في حفـظ الـتراث البشرى، كما سهلت الطباعة تبادل الأفكار والاراء بين العلماء والأدباء في أخحاء العـالم كافة متخطية حواجز الزمان والمكان. 13 ومهارات الكتابة إحدي مهارات اللغوية الكليـة : الاسـتماع والـكلام والقـراءة، وتعد هذه المهاراة حديثة نسبيا إذا قورنت بمهارتي الاستماع والكلام. لأن الكتابة اختراع يشري ظهر في عصور لاحقة، وشكل اخـتراع الكتابـة مرحلـة جبـــة في تقـدم الحضــارة الإنسانية. والكتابة مهارة علاقة قوية وطيدة بمهارات اللغة الأخرى، فالرمز الكتابي يجمع بين الكتابة وبين القراءة كما تشـترق الكتابـة في صـفة الإنتاجيـة مـع مهـاراة الـكلام،

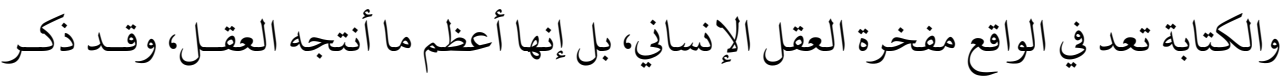
علماء الانثربولوبي أن الإنسان حين اخترع الكتابة بدأ تاريخه الحقيقي.14

$$
13 \text { 13 } 13 \text { عبد الحميد عبد الله، أسس إعداد الكتب لتعليمية لغير الناطقين با العربية، (دار الاعتصام) ص:63 الصديق عبدالله، تعليم اللغة العربية للناطقين بغيرها، } 2008 \text { م، ص:111 }
$$


ولما كانت الكتابة أداة اتصال لغوية، ووسيلة تحمل فكر الإنسان وتفكيره واراءه تجاه الأخرين، وبقدر ما في الكتابة من حسن العرض ووضوح الكلمات وانسجام الحروف وجمال الشكل، يكون القارى متمكنا من فهم ما هـو مكتـوب مطمئنـا إليـه، وإن سـوء الكتابة يضيع دلالات المعاني، ويطمس معالم الأفكار.15 والكتابة تعتبر أعظم ما أنتجه العقل الإنساني عبر تاريخه الطويل واسـتطاع أن يسجل إنتاجه وتراثه، ليضع أمام الأجيال القادمة فكر الإنسان مسجلا في نقـاء وصـفاء "ولقد ذكر علماء الأنثر وبولوبي أن الإنسان حيث اخترع الكتابة بــأ تاريخـهـ الحقيـق، وبهذا تعتبر الكتابة وسيلة من وسائل الاتصال الإنساني، والتي يتم بواسطتها الوقـوف على أفكار الغير، وللتعبير عما لدين من معان ومفاهيم ومشاعر، وتسجيل ما نود تسجيل مـن حوادث ووقائح، فكثيرا ما يكون الخطأ في الرسم الإملاء، وعدم جودة الكتابة، وضـعف التعبير، عما في النفس من أفكار زمفاهيم، سببا في قلب المعنى. نحن نعرف أن قوانين الكتابة العربية من أهم المهارات الأساسية، ونحن نتعلمهـا صغارا، ولكنناننساها كبيرا، لأننا نفرق بين التعليم من أجل النجاح، والتعليم من أجـل الاستفادة. وليس التذكير بهذه القواعد من باب الغلو في محبة الثيء والتعصب له، فنحن لا نفترض نسيانها، بقدر ما نري إلى التذكير.16 وفي تعليم الكتابة يعني الاهتمام بـأمور ثلاثـة رئيسـية : أولهـا الكتابـة بشـكل يتصف بالأهمية، والاقتصادية، والجمال، ومناسبته لمقتضى الحال، وهذا ما يسمى، بالتعبير

$$
\text { 16 رضوان، المرجع السابق، صمود شاكر سعيد، المرشد في الإملاء، (المملكة العربية السعودية 1988-1996) ص:5 }
$$

Kariman, Volume 06, Nomor 02, Desember 2018|299 


\section{Bambang Hermanto}

التحريري.وثانيا، الكتابة السليمة مـن حيـث الهجــاء، وعلامــات الترقـيم والمشـكلات الكتابة الأخرى، كالممزات، وغير ذلك. وثالثهـا، الكتابـة بشـكل واضـح جميـل. فالثـاني والثالث هنا يتصلان بالمهـارات اليدويـة في الكتابـة، أو مـا يسـمى باليـات الكتابـة، أو

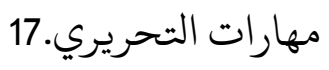

ووجب علينا أن نعلم التلاميذ الكتابة الصـحيحة ليقـدروا على رسـم الحــروف الصحيحة حتى يقدروا على كتابة ما من أفكارهم بوضوح ودقة. ويتركز الباحث في العناية على اهتمـام كتابـة الصـحيحة لدى التلاميـذ، لأن الكتابـة الصـحيحة تــؤثر صـحيح ووضوحه.18

والكتابة هي وسيلة من وسائل الاتصال الإنسان، يتم عـن طريقهـا التعـرف على أفكار الغير، والتعبير عما لدى الفرد مـن معـان ومفــاهيم ومشـاعر وتسـجيل الحــوادث والوقائع. وكثيرا ما يكون الخطأ الكتابي في الرسم، أو في عرض الفكـــة، سـبب في تغيـير المعنى وعدم وضوح الفكرة. لذلك تعتير الكتابة الصحيحة عملية مهمـة في التعلـيم، إذا أنها عنصر أسسي في عناصر الثقافة، وضرورة اجتماعيـة لنقـل الأفـكار والتعبـير عنهـا،

$$
\text { والوقوف على أفكار واراء الأخرين والإلمام بها.19 }
$$

وتظهر أهمية الكتابة في حيات الدارسين والتلاميذ بصفة خصـة في أنهـا تسـهل

لهم أشياء كثيرة عندما يزاولون الاتصال بـالاخرين والتعبـير عـن أفكارهـم، كمــا أنهـم يحتاجون إليها في كتاب المذكرات الشخصية وفي ملء الاستمارات الخاصـة، وقبـل هـذا

$$
\begin{aligned}
& 17 \text { محمد لحمر مركور، تدريس فنون اللغة العربية، 1991، ص:265 }
\end{aligned}
$$

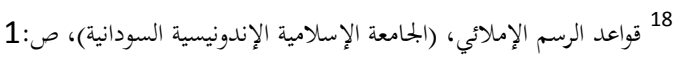

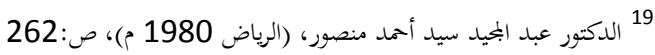


وذاك فهي وسيلة التعليم وتمكنهم من القدرة في الإجابة عن أسئلة الاختبارات المطلوبة

$$
\text { منهم تحريريا. }
$$

وتعد مهارة الكتابة من المهارات اللغوية المركبة حيث تتطلب أكـثر مسن حاسـة

للعمل فيها، فاليد تخط، والعين تتابع، والعقل يراقب ويـنظم، ومــن أجـل هــذا التعقيـــ

والتركيب أتى تعليم الكتاية في نهاية تعليم المهارات اللغوية، لـيس إقـلالا مسن أهميتهـا

ولكن لأنها مهارة لا يمككن السطرة عليهـا إلا بعـد أن يسـتمع الدراس للغـة ويــألف أصواتها، ثم يحاكيها نطقا وحديثا ثم يعرف رموزها في القران وأخرا يكتبها. والكتابة تشتمل الخط والإملاء والتركيب والتعبير، وإذا أهمل عنصر-مـن هـذه العناصر فإنه يؤدي إلى إخفاق المعنى وضياع الغرض منها، وكم من أفـكار راقيـة، ومعـان سامية، وأفكار مبدعة

وتفكير خلاق حط منها خط هزيل، أو عدم مراعاة قواعد الكتابة مــا أدى بهـا

$$
\text { إلى إعجاز الفكر الراقي عن النهوض والتحليق في أجواء المعنى20 }
$$

وتعتبر الكتابة من الوظائف الأساسية للمدرسين الإبتدائية، ومن ابرز مسؤليتها

وهي تمثيلة فنا من فنون اللغة الأربعة، وهي الفن للقابل للقراءة مسن حيـث الأهميـة في بناء المواطن إذ يختلفان (القراءة والكتابة عن الاستماع والحــديث، حيـث أنهـا يمـثلان مواقف مؤقته تنتهي بانتهاء زمنها في الحياة اليومية).21

$$
20 \text { نفس المرجع، ص:64 } 21 \text { دكتور إبراهبم محمد عطا، طرق تدريس اللغة العربية والتربية الدينية. (1416 - 1996)، ص:175 }
$$

Kariman, Volume 06, Nomor 02, Desember 2018| 301 


\section{Bambang Hermanto}

إن الكتابة في مجال الأعمــال تختلـف عـن الكتابـة في بقيـة المجــالات، فاللغـة

المستخدمة واقعية، ووجهة النظر واضحة، وكل النقاط مشروحة بشكل جيد ومفهوم.

إن امتلاك موهبة الكتابة بشكل جيد بالنسبة للأشخاص الذيـن تعتـبر الكتابـة

جزءً لايتجزأ من عملهم هو عون كبير هؤلاء الأشخاص ، مع الإشارة بأن الكتابة بشـكل جيد ليست بالثيء السهل أو البسيط، حتى أن الكتَاب المخضر-من يمكـن أن يمـروا بلحظات ضعف وعجز أمام الكتابة، ولكنها كغيرها من المهارات يمكن أن تعزز وتنمي

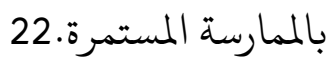

لاشك لنا أن نعلم طريقة الكتابة الجيدة، إنها الرواية التي لانستطيع تركها، إنهـا القصيدة التي لا ننساها، إنها الخطاب الذي بمقدوره أن يصنح فارقاً في حياتنـا وأن يغـير من كيفية نظرنا إلى هذه الحياة، إنها تلك المذكرة التي باستطاعتها أن تشـعل الحمـاس في نفوسنا وتقودنا للعمل، إنها الرسالة التي تتكلم ما ليس باستطاعة أي مكلمة أن تقوله. كذلك يرى عبد الحميد عبد الله وناصر عبد الله الغالى بأن الكتاب المدرسى هو الكتاب الأساسى للطالب ومايصحبه من مواد تعليمية مساعدة والـتى تؤلـف مـن قبـل المتخصصين في التربية واللغة، وتقدم للدارسين لتحقيق أهداف معينة في مقرر معينة، في مرحلة معينة بل في صف دارسى معـين وفي زمسن محـدد.23 والكتابـة إحــدى المهـارات الأساسية في نعليم اللغة الأولى واللغة الأجنبية على حد سواء.24

222 دكتور محمد علي الخولي، تعليم اللغة حالات وتعليقات،(جامعة الملك سعود 1998)، ص:91

23 عبد الحميد عبد الله الغالي، أسس إعداد الكتب التعليمية لغير الناطقين بالعربية، (دار الاعتصام)، صاليم: 9

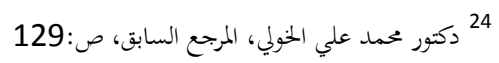


وقد بلغة الكتابة غايتها من الإتقان والجودة في دولـة التباعـة، حـين رقيـت في

$$
\begin{aligned}
& \text { الحضارة والشرف حتى صارت الكتابة تنسب إليهم. كما قال الشاعر : }
\end{aligned}
$$

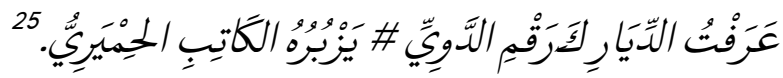

$$
\begin{aligned}
& \text { ومن بعض العلماء يقول: }
\end{aligned}
$$

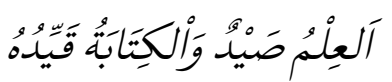

يتناول هذا البحث تعلـيم الإمـلاء، فيعـرض أهميـة الكتابـة، ومشـكلات

الكتابة العربية، ، ومفهوم الإملاء وأبعاده، ويكتل الإملاء منزلة كبـيرة بـين فـروع

اللغة. فهي من الاسس المهمة للتعبير الكتابى. فإذا كانت قواعد النحو والصرف وسيلة

لصحة الكتابة من الناحية الإعرابية، والاشتقاقية، فإن الإملاء وسيلة لها مـن حيـث

$$
\text { الصورة الخطية. }
$$

والكتابة هي الأداة الرئيسية لنقل الفكرة مـن الكتـاب إلى القـاريء نقـلا

سليما ووسيلة الإتصال بالتراث المكتوب ووسيلة مـن وسـائل التماسـك الإجتمـاعي

ووسيلة من وسائل اكتساب الثقافة ومظهر من مظـاهر الشخصـية حيـث أن عـدم

تمكن الفرد منها على أن مستوى من مستويات التعليم يقلل من قيمته. 27

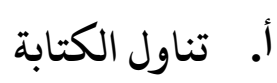

ومن خلال هذا التعريف نرى أن الكتابة تتناول ثلاثة جوانب هي :

$$
\begin{aligned}
& 25 \text { حسين والي، كتاب الإملاء، (بيروت - لبنان 1406هـ - } 1986 \text { م) }
\end{aligned}
$$

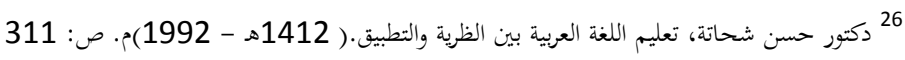

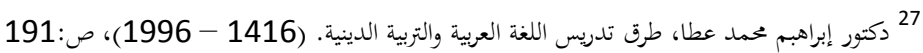

Kariman, Volume 06, Nomor 02, Desember 2018|303 


\section{Bambang Hermanto}

1) الخط الواضح ومهاراته الفرعية مثل : مراعاة الحروف التي تكتب فوق

السطر والحروف التي تنزل عنه، والحروف المطموسـة وغـير المطموسـة،

$$
\text { وأسنان الحروف وغير ذلك. }
$$

2) النهج السليم لحروف الكلمات، بمعنى مراعاة ترتيب حروف الكلمة وفق

\section{نطقها.}

3) تركيب الجمل وتضافرها بحيث تحمل معـنى ومضــمونا، ويتضـمن هـــا

$$
\text { العنصر مراعاة القواعد النحوية والصرفية في الكتابة. } 28
$$

و المكانة الكتابة الثقافية اتجهت العناية إلى ترتيب التلاميذ على أمور ثلاثة :

1) قدرة التلاميذ على الكتابة الصحيحة، أي رسم الحروف رسما صحيحا.

2) إجادة الخط، أي كتابة الكلمات بالطريقة التي اتفق عليها أهل اللغة.

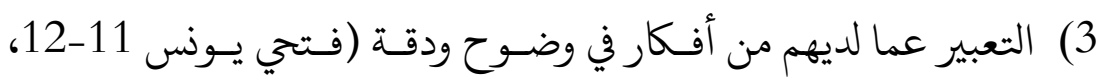

1987) ذلك أن الكتابة من العناصر الأساسية في العملية التربوية، وفي

تعليم اللغة كما أنها تمثل من بين المهارات اللغوية مهاراة الإؤسل.29

$$
29 \text { نمس المربع، ص:63 إبرهيم الخطيب، طرائق تعليم اللغة العربية، } 1424 \text { هـ - } 2003 \text { م، ص:115 }
$$

